\title{
Analisis Kegiatan Stimulasi Motorik Kasar untuk Anak Usia 5- 6 Tahun pada Film Upin Ipin
}

\author{
Erlin Windawati*, Usep Kustiawan, Wuri Astuti \\ Universitas Negeri Malang, Jl. Semarang No. 5 Malang, Jawa Timur, Indonesia \\ *Penulis korespondensi, Surel: erlinwindawati97@gmail.com
}

Paper received: 5-7-2021; revised: 23-7-2021; accepted: 30-7-2021

\begin{abstract}
Gross motor skills are the most important skills in growth and development in early childhood. There are many things that can exemplify gross motor activities to be applied to early childhood, one of which is the cartoon film Upin Ipin. This research is motivated by the large number of televisions that broadcast unfavorable content for children. It is different from the cartoon Upin Ipin which shows educational values, one of which is gross motoric activities. The purpose of this study was to analyze the gross motoric activities in the Upin Ipin film on the suitability of children aged 5-6 years based on Permendikbud No.137 of 2014. This study used a qualitative approach with the type of activity analysis. The instrument in this study besides the researcher as an instrument, the researcher used a data card. The results of this study indicate that the gross motor activities in the Upin Ipin film correspond to the stages of children aged 5-6 years.
\end{abstract}

Keywords: activity; stimulation; gross motor; children aged 5-6 years; upin ipin film

\begin{abstract}
Abstrak
Motorik kasar merupakan keterampilan yang paling utama dalam pertumbuhan dan perkembangan pada anak usia dini. Banyak hal yang dapat mencontohkan kegiatan-kegiatan motorik kasar untuk menstimulasi anak usia dini, salah satunya melalui film kartun Upin Ipin. Penelitian ini dilatarbelakangi banyaknya televisi yang menayangkan konten kurang baik untuk anak. Berbeda dengan film kartun Upin Ipin yang menayangkan nilai-nilai pendidikan, salah satunya kegiatan motorik kasar. Tujuan dari penelitian ini untuk menganalisis kegiatan motorik kasar yang ada pada film Upin Ipin terhadap kesesuaian anak usia 5-6 tahun berdasarkan Permendikbud No.137 Tahun 2014. Penelitian ini menggunakan pendekatan kualitatif dengan jenis analisis kegiatan. Instrumen pada penelitian ini selain peneliti sebagai instrumen, peneliti menggunakan kartu data. Hasil dari penelitian ini menunjukkan bahwa kegiatan motorik kasar yang ada pada film Upin Ipin sesuai dengan tahapan anak usia 5-6 Tahun.
\end{abstract}

Kata kunci: kegiatan; stimulasi; motorik kasar; anak usia 5-6 tahun; film upin ipin

\section{Pendahuluan}

Masa anak usia dini (AUD) dapat diartikan sebagai masa emas anak atau golden age dengan usia 0-6 tahun. Pada masa emas inilah anak akan mendapat berbagai stimulus dan rangsangan yang diberikan oleh orangtua dan guru agar anak dapat melatih dan mengembangkan aspek psikomotoriknya. Pada masa emas ini pula anak bebas melakukan aktivitas atau kegiatan yang anak inginkan agar perkembangan anak dapat tumbuh secara optimal sesuai dengan tahapan usianya. Oleh karena itu masa ini menjadi masa istimewa bagi anak. Motorik merupakan gerakan yang melibatkan seluruh anggota tubuh yang memerlukan tenaga dan otot besar dalam melakukan usaha, kegiatan dan aktivitas-aktivitas lainnya. Hurlock (1978:159) mengungkapkan bahwa perkembangan motorik merupakan perkembangan yang dikendalikan oleh gerakan anggota tubuh dan otak sebagai pusat gerakan yang matang. Gerakan motorik dibedakan menjadi dua, yaitu gerakan motorik kasar dan gerakan motorik halus. 
Menurut bahasa Indonesia, kata "motor" diartikan sebagai gerak pada tubuh atau gerakan tanpa memberikan perbedaan didalamnya. Motorik merupakan gerakan internal yang berasal dari dalam tubuh, konsisten serta sukar diamati. Sedangkan movement merupakan gerak yang memiliki sifat eksternal yang berasal dari luar tubuh serta mudah diamati. Keterampilan motorik pada anak usia dini sangat dibutuhkan agar anak dapat mengembangkan kemampuannya dalam bidang pengembangan bahasa, kognitif, seni dan kreatifitas, (Triyana, 2017).

Decaprio (2017) menjelaskan motorik merupakan gerakan-gerakan yang terjadi pada seluruh tubuh. Gerakan motorik ini berhubungan dengan kemampuan pengendalian gerak tubuh pada anak. Gerak pengendalian ini terjadi pada tangan dan kaki untuk mengendalikan kegiatan-kegiatan motorik kasar yang dilakukan anak. Oleh sebab itu perlu adanya latihanlatihan atau stimulus yang diterima anak agar otot pada kaki dan tangan anak kuat, terutama bagian kaki sebagai penopang beban dalam pengendalian gerak

Menurut Sumantri dalam (Nugraheni: 2019) ada beberapa fungsi perkembangan motorik kasar anak, yaitu : (a) sebagai alat ukur dalam pertumbuhan dan perkembangan kesehatan anak, (b) memperkuat daya tahan tubuh anak, (c) melatih keterampilan kelincahan gerak, (d) meningkatkan aspek perkembangan yang dimiliki anak, dan (e) memberikan perasaan senang terhadap anak ketika anak mampu menyelesaikan tugas atau kegiatan yang berhubungan dengan keterampilan motorik.

Kemampuan motorik anak menjadi salah satu kemampuan anak usia dini yang berkembang dengan sangat pesat seiring berjalannya usia. Hal ini dapat terlihat jelas sejak anak lahir, kemampuan motorik anak dapat terlihat pada saat anak menggerakkan tangan dan kakinya. Kegiatan motorik ini akan terus terlihat dan berkembang hingga anak beranjak dewasa, dengan melakukan gerakan seperti melompat, menendang, berlari, berguling dan sebagainya. Oleh sebab itu perlu adanya stimulus yang diberikan agar kemampuan motorik anak dapat tumbuh dan berkembang dengan optimal. Perkembangan kemampuan motorik anak akan tumbuh dan berkembang dengan optimal apabila anak mendapatkan kesempatan dan rangsangan yang diberikan orang tua kepada anak untuk melakukan aktivitas atau kegiatan yang melibatkan tubuh dan anggota geraknya. Tahapan perkembangan motorik kasar anak berdasarkan Standar Tingkat Pencapaian Perkembangan Anak Usia 5-6 tahun sebagai berikut:

Tabel 1. Tahap Perkembangan Motorik Anak Usia 5-6 Tahun

\begin{tabular}{ll}
\hline \multicolumn{1}{c}{ Lingkup Perkembangan } & \multicolumn{1}{c}{ Tingkat Pencapaian Perkembangan Anak Usia 5-6 tahun } \\
\hline Fisik-motorik & 1. Melakukan gerakan tubuh secara terkoordinasi untukmelatih \\
Motorik Kasar & kelenturan, keseimbangan dan kelincahan, \\
& 2. Melakukan koordinasi gerakan kaki, tangan, dan kepala dalam \\
& menirukan tarian atau senam, \\
& 3. Melakukan permainan fisik dengan aturan, \\
& 4. Terampil dalam menggunakan tangan kanan dan kiri, \\
& 5. Melakukan kegiatan kebersihan. \\
\hline
\end{tabular}

Sumber: Permendikbud No. 137 Tahun 2014 Lampiran I (STPPA)

Tujuan motorik kasar yaitu untuk meningkatkan kemampuan keterampilan motorik kasar sesuai karakteristik anak agar berkembang dengan baik dan meningkatkan rasa percaya 
diri anak sebagai bekal dimasa mendatang. Baan (2020) motorik kasar untuk anak usia dini memiliki beberapa tujuan yaitu, untuk mengenalkan kepada anak tentang gerakan-gerakan kasar dengan menggunakan otot besar, melatih gerakan kasar yang anak lakukan, mengembangkan keterampilan mengelola, mengontrol gerakan tubuh serta koordinasinya, dan juga meningkatkan kemampuan motorik anak serta menerapkan cara hidup sehat dalam keseharian anak usia dini. Semakin sering dan terlatih anak usia dini dalam menggunakan otot-otot besar dalam melakukan kegiatan, maka semakin kuat otot-otot anak bahkan membuat jasmani anak sehat. Anak juga tidak akan minder apabila bermain bersama teman sebayanya apabila perkembangan motorik anak sesuai dengan tujuannya.

Kegiatan motorik selain memberikan rasa senang terhadap anak, juga memberikan dampak yang terjadi terhadap motorik kasar anak. Romlah (2017) menyatakan dampak kegiatan motorik kasar bagi anak yaitu, dapat mengembangkan kreatifitasnya melalui kegiatan-kegiatan motorik kasar yang anak lakukan. Semakin meningkat perkembangan motorik anak, maka semakin meningkat juga kreatifitas yang anak miliki. Hal ini menunjukkan dampak positif terhadap kemampuan motorik anak. Sebaliknya, jika perkembangan motorik anak menurun atau tidak berkembang, maka kreatifitas anak juga akan menurun dan bahkan tidak bisa berkembang sesuai tahapan usianya. Dampak ini menunjukkan dampak negatif, dan dapat terjadi apabila anak kurang mendapatkan stimulus motorik kasar. Kreatifitas yang dimaksudkan dalam pembahasan ini dapat dicontohkan ketika anak bermain fisik dengan aturan, seperti hula hoop, menggiring bola, bermain lompat tali, engklek, dan bakiak.

Televisi selain digunakan untuk sarana hiburan, juga dapat digunakan sebagai sarana belajar untuk mendapatkan ilmu pengetahuan dan pembelajaran untuk mendidik anak bahkan orang dewasa sekaligus. Salah satu program televisi yang dapat memberikan pengalaman dan pembelajaran untuk anak usia dini yaitu film kartun atau film animasi yang juga sangat digemari oleh anak-anak karena menghibur dan sesuai dengan kehidupan sehari-hari anak usia dini. Saat ini Indonesia dibanjiri film kartun yang berasal dari dalam dan luar negeri yang membuat anak usia dini terhibur.

Daryanto dalam (Nurwita 2019) menyebutkan bahwa film kartun merupakan gambaran tentang seseorang, serta imajinasi atau keadaan sehari-hari yang ditunjukkan dalam bentuk lukisan yang unik dan menarik. Film animasi atau biasa disebut film kartun merupakan media yang menampilkan karya gerak dari hasil rangkaian gambar. Film ini memberikan pesan atau motivasi pembelajaran secara audio visual yang memberikan unsur gerak. Media ini menimbulkan rasa ketertarikan dan diterima baik oleh penonton terutama anak usia dini.

Salah satu film yang digemari anak-anak yaitu film kartun Upin Ipin yang berasal dari luar negeri. Film Upin Ipin selain menghibur, juga bernilai positif dan memberikan edukasi dalam pembelajaran anak usia dini baik di sekolah maupun di kehidupan sehari-hari. Film Upin Ipin adalah film kartun yang berasal dari Malaysia dengan memerankan anak kembar bernama Upin Ipin yang tinggal bersama dengan nenek dan kakaknya yang memberikan pengalamanpengalaman pembelajaran sesuai kehidupan nyata anak usia dini.

Nurwita (2019) menyatakan tayangan film kartun Upin dan Ipin merupakan suatu bentuk program tayangan yang diproduksi oleh ahli pembuat film. Film ini memberikan tokoh sepasang anak kembar kecil yang bernama Upin Ipin dan mereka hidup dalam keadaan sederhana. Film ini ditayangkan melalui proses dari gambar interpretative dengan menyertakan simbol-simbol dalam menyampaikan pesan secara ringkas terhadap penonton, dan 
menarik perhatian anak-anak ketika menonton film Upin Ipin, karena film ini menayangkan kehidupan nyata sesuai usia anak usia dini tentang dunia anak

Berdasarkan penelitian terdahulu yang dilakukan oleh Purnamasari (2020) tentang "Pengaruh Film Kartun Upin Ipin Terhadap Perilaku Anak". Hasil penelitian ini membuktikan bahwa anak mampu mencontoh perilaku serta menerapkan kegiatan-kegiatan motorik yang ada pada film upin ipin, termasuk pada kegiatan motorik kasar yang terdapat pada film kartun Upin Ipin dengan baik karena film ini sesuai dengan tahapan anak usia dini. Perbedaan penelitian terdahulu dengan penelitian ini, pada penelitian ini peneliti memfokuskan kegiatan motorik kasar yang ada pada film Upin Ipin berdasarkan STPPA Permendikbud No.137 Tahun 2014 yang terkandung dalam tema "Sedia Mulai Bagian 1 dan 2, Taman Mesra dan Jom Hidup Sihat".

\section{Metode}

Penelitian ini menggunakan pendekatan kualitatif dan menggunakan jenis penelitian analisis kegiatan. Metode ini peneliti gunakan karena peneliti akan menganalisis kegiatan motorik kasar yang ada pada film Upin Ipin untuk anak usia 5-6 tahun yang sesuai dengan Permendikbud N0.137 Tahun 2014 tentang STPPA. Data sekunder peneliti gunakan agar dapat memperjelas dan melengkapi hasil dari film yang akan dianalisis, seperti jurnal, buku, artikel dan lain-lain. Sumber data pada penelitian ini melalui soft copy film kartun Upin Ipin agar peneliti mudah mengamati kegiatan secara berulang. Teknik pengumpulan data berupa observasi dan dokumentasi kegiatan motorik kasar yang ada pada film Upin Ipin.

Selain peneliti sebagai instrumen utama, peneliti menggunakan kartu data. Kartu data digunakan agar peneliti dapat dengan mudah mengolah dan mengelompokkan data yang didalamnya mengandung objek atau kegiatan motorik kasar yang ada pada film Upin Ipin. Kartu data yang peneliti gunakan sebagai berikut:

Tabel 2. Kartu Data Kegiatan Motorik Kasar pada Film Upin Ipin

\begin{tabular}{|l|l|l|c|}
\hline Kegiatan Motorik & Kode Judul & Kode Kutipan & $\begin{array}{c}\text { Dampak Terhadap Kemampuan } \\
\text { Motorik Anak }\end{array}$ \\
\hline & & & \\
\hline & & & \\
\hline & & & \\
\hline & & & \\
\hline
\end{tabular}

Keterangan:

Kegiatan Motorik $\quad$ : Kegiatan motorik apa yang dilakukan

Kode Judul : : Singkatan tema pada film Upin Ipin

Kode Kutipan : : Episode yang terdapat kegiatan motorik

Dampak : Dampak terhadap perkembangan motorik anak

Teknik analisis data pada penelitian ini menggunakan analisis isi konten. Analisis isi konten kualitatif ini selain dapat memfokuskan isi dari kegiatan motorik, juga dapat digunakan untuk mengetahui isi komunikasi yang ada pada film Upin Ipin. Analisis isi konten ini diperoleh melalui hasil observasi / mengamati kegiatan motorik kasar yang ada pada film Upin Ipin dan dokumentasi untuk selanjutnya dianalisis.

Uji keabsahan data menggunakan peningkatan ketekunan. Peningkatan ketekunan dilakukan dengan cara mengamati kegiatan motorik kasar yang ada pada film Upin Ipin secara 
terus menerus melalui soft copy. Peningkatan ketekunan bertujuan agar peneliti dapat memahami lebih dalam lagi kegiatan motorik kasar yang ada pada film Upin Ipin sesuai usia anak 5-6 tahun berdasarkan pedoman Permendikbud No.137 Tahun 2014.

\section{Hasil dan Pembahasan}

\subsection{Hasil Penelitian Menggunakan Kartu Data}

Setelah peneliti melakukan pengamatan pada tiga episode atau tiga musim dalam film kartun Upin Ipin musim 5 bagian 1 dan 2, musim 6 dan musim 11 didapat data berupa kutipan adegan yang kemudian dianalisis kegiatan motoriknya. Berdasarkan hasil analisis, terdapat sepuluh kegiatan motorik kasar yang sesuai dengan Permendikbud No.137 Tahun 2014 pada ketiga musim film kartun Upin Ipin. Kartu data mengenai kegiatan motorik disajikan dalam tabel sebagai berikut:

Tabel 3. Kartu Data Kegiatan Motorik

\begin{tabular}{|c|c|c|c|c|}
\hline No & Kegiatan Motorik & Kode Judul & $\begin{array}{c}\text { Kode } \\
\text { Cuplikan } \\
\end{array}$ & $\begin{array}{c}\text { Dampak Terhadap Kemampuan } \\
\text { Motorik Anak }\end{array}$ \\
\hline \multirow[t]{2}{*}{1} & $\begin{array}{l}\text { Melakukan gerakan tubuh secara } \\
\text { terkoordinasi untuk melatih }\end{array}$ & SM bagian 1 & M5 & $\begin{array}{l}\text { Dampak yang terjadi terhadap } \\
\text { motorik anak yaitu terlatihnya }\end{array}$ \\
\hline & $\begin{array}{l}\text { kelenturan (pemanasan / } \\
\text { pelenturan badan sebelum } \\
\text { melakukan aktivitas senam) }\end{array}$ & JHS & M11 & $\begin{array}{l}\text { kekuatan otot pada tubuh anak. } \\
\text { Anak juga akan terbiasa } \\
\text { melakukan kegiatan pemanasan } \\
\text { sebelum melakukan aktivitas } \\
\text { motorik karena anak sudah } \\
\text { mendapatkan stimulasi dengan } \\
\text { mencontoh kegiatan yang anak } \\
\text { lihat dan terapkan agar otot tubuh } \\
\text { anak tidak mengalami cidera atau } \\
\text { kram. }\end{array}$ \\
\hline 2 & $\begin{array}{l}\text { Melakukan koordinasi gerakan } \\
\text { kaki, tangan, dan kepala dalam } \\
\text { menirukan senam atau tarian } \\
\text { (menirukan senam irama) }\end{array}$ & JHS & M11 & $\begin{array}{l}\text { Dampak yang terjadi terhadap } \\
\text { motorik anak yaitu, dapat melatih } \\
\text { dan mengembangkan } \\
\text { kreatifitasnya melalui senam } \\
\text { irama. Dampak lain terhadap anak } \\
\text { yaitu, membuat tubuh anak } \\
\text { menjadi sehat, bugar dan motorik } \\
\text { anak berkembang dengan optimal, } \\
\text { karena senam irama berhubungan } \\
\text { dengan kemampuan pengendalian } \\
\text { gerak pada tubuh anak, yaitu kaki, } \\
\text { tangan, kepala, dan lain-lain. }\end{array}$ \\
\hline \multirow[t]{8}{*}{3} & $\begin{array}{l}\text { Melakukan permainan fisik dengan } \\
\text { aturan }\end{array}$ & & & $\begin{array}{l}\text { Dampak yang terjadi terhadap } \\
\text { motorik anak yaitu, dapat melatih }\end{array}$ \\
\hline & Hulahoop & SM bagian 1 & M5 & dan mengembangkan \\
\hline & Menggiring Bola & SM bagian 1 & M5 & kreatifitasnya melalui kegiatan- \\
\hline & Lompat Tali & SM bagian 1 & M5 & kegiatan yang dilakukan seperti \\
\hline & Engklek & SM bagian 2 & M5 & bermain dengan aturan. Karena \\
\hline & Balap Karung & SM bagian 2 & M5 & semakin anak terstimulus \\
\hline & Bakiak & SM bagian 2 & M5 & melakukan kegiatan motorik, \\
\hline & Tarik Tambang & SM bagian 2 & M5 & $\begin{array}{l}\text { maka semakin meningkat pula } \\
\text { kreatifitas yang anak miliki. }\end{array}$ \\
\hline 4 & $\begin{array}{l}\text { Terampil dalam menggunakan } \\
\text { tangan kanan dan kiri: }\end{array}$ & & & $\begin{array}{l}\text { Dampak yang terjadi terhadap } \\
\text { motorik anak yaitu, melatih dan }\end{array}$ \\
\hline
\end{tabular}




\begin{tabular}{|c|c|c|c|c|}
\hline No & Kegiatan Motorik & Kode Judul & $\begin{array}{c}\text { Kode } \\
\text { Cuplikan } \\
\end{array}$ & $\begin{array}{c}\text { Dampak Terhadap Kemampuan } \\
\text { Motorik Anak }\end{array}$ \\
\hline & $\begin{array}{l}\text { Menghias ban bekas dan } \\
\text { memindahkannya }\end{array}$ & TM & M6 & \multirow{3}{*}{$\begin{array}{l}\text { mengembangkan kreatifitas } \\
\text { motorik anak. Selain kreatif dalam } \\
\text { menghias ban bekas, kekuatan otot } \\
\text { tangan anak akan terlatih dan } \\
\text { terstimulus dengan baik melalui } \\
\text { kegiatan-kegiatan sederhana. } \\
\text { Karena semakin anak } \\
\text { mendapatkan stimulus dan latihan } \\
\text { terhadap motorik anak, kekuatan } \\
\text { otot tangan dan kaki anak akan } \\
\text { berkembang dengan optimal. } \\
\text { Dampak yang terjadi terhadap } \\
\text { motorik anak yaitu, anak akan } \\
\text { lebih sering melalukan kegiatan } \\
\text { kebersihan. Karena anak sudah } \\
\text { mengetahui bahwa selain menjaga } \\
\text { lingkungan, kegiatan kebersihan } \\
\text { juga berdampak postif untuk } \\
\text { jasmani anak. Anak akan tumbuh } \\
\text { dan berkembang dengan optimal. }\end{array}$} \\
\hline & Badminton & JHS & M11 & \\
\hline 5 & $\begin{array}{l}\text { Melakukan kegiatan kebersihan } \\
\text { (Membersihkan halaman taman) }\end{array}$ & TM & M6 & \\
\hline
\end{tabular}

\subsection{Analisis Kegiatan Motorik Kasar Pada Film Upin Ipin dengan Permendikbud No.137 Tahun 2014 Tentang STPPA}

Setelah peneliti melakukan pengamatan pada tiga episode atau tiga musim dalam film kartun Upin Ipin musim 5 bagian 1 dan 2, musim 6 dan musim 11 didapat data berupa kutipan adegan yang kemudian dianalisis kegiatan motoriknya. Berdasarkan hasil analisis, terdapat sepuluh kegiatan motorik kasar yang sesuai dengan Permendikbud No.137 Tahun 2014 pada ketiga musim film kartun Upin Ipin. Kartu data mengenai kegiatan motorik disajikan dalam tabel sebagai berikut:

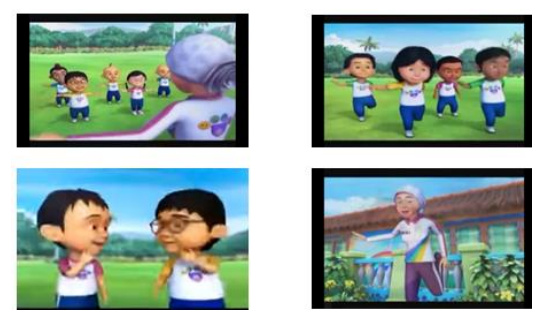

Gambar 1. Kegiatan Motorik Kasar Pada Film Kartun Upin Ipin Pada Musim 5 Tema Sedia Mulai Bagian 1

Gambar 1 adalah hasil screenshot kegiatan motorik yang sesuai dengan tahapan anak usia 5-6 tahun sesuai Permendikbud No.137 Tahun 2014. Kegiatan ini berupa melakukan gerakan tubuh secara koordinasi untuk melatih kelenturan, keseimbangan dan kelincahan. Terlihat Upin Ipin dkk beserta Cikgu Jasmin melakukan gerakan pemanasan/pelenturan sebelum memulai kegiatan motorik lainnya. Cikgu Jasmin memberikan contoh kemudian Upin Ipin dkk menirukannya. 


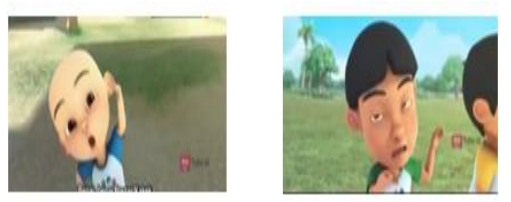

\section{Gambar 2. Kegiatan Motorik Kasar Pada Film Kartun Upin Ipin Pada Musim 11 Tema Jom Hidup Sihat}

Gambar 2 adalah hasil screenshot kegiatan motorik yang sesuai dengan tahapan anak usia 5-6 tahun sesuai Permendikbud No.137 Tahun 2014. Kegiatan ini berupa melakukan gerakan tubuh secara koordinasi untuk melatih kelenturan, keseimbangan dan kelincahan. Terlihat Ipin dan Mail melakukan kegiatan pelenturan sebelum melakukan senam agar otot tidak cedera/tidak kram. Kegiatan pelenturan yang dilakukan sesuai dengan tahapan usia anak dan mudah dicontoh untuk dilakukan.

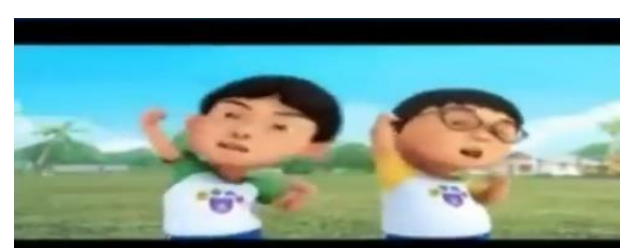

\section{Gambar 3. Kegiatan Senam Irama Pada Film Upin Ipin Pada Musim 11 Tema Jom Hidup Sihat}

Gambar 3 adalah hasil screenshot kegiatan motorik yang sesuai dengan tahapan anak usia 5-6 tahun sesuai Permendikbud No.137 Tahun 2014. Kegiatan ini berupa senam irama. Terlihat Mail dan Ehsan melakukan senam irama pada musim 11. Kegiatan senam irama pada scene ini sesuai dengan tahapan usia anak dan mudah dilakukan anak. Kegiatan senam irama selain menghibur, juga membuat tubuh menjadi sehat.
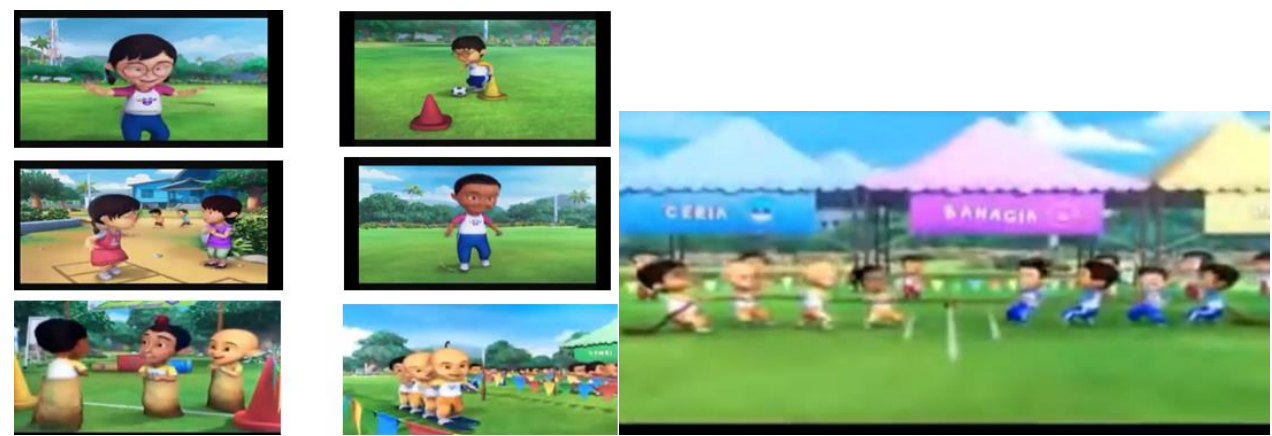

Gambar 4. Melakukan Permainan Fisik Dengan Aturan Musim Pada 5 Tema Sedia Mulai Bagian 1 dan Bagian 2

Gambar 4 adalah hasil screenshot kegiatan motorik yang sesuai dengan tahapan anak usia 5-6 tahun sesuai Permendikbud No.137 Tahun 2014. Kegiatan yang Upin Ipin dkk lakukan berupa beberapa kegiatan permainan fisik dengan aturan. Kegiatan ini ditujukkan pada permainan hulahoop, menggiring bola dengan zig-zag, engklek, lompat tali, balap karung, bakiak dan tarik tambang. Beberapa kegiatan ini sesuai dengan usia anak dan anak mampu menerapkannya. 


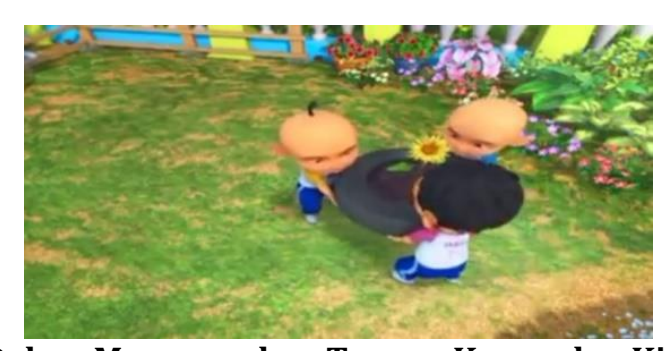

\section{Gambar 5. Terampil Dalam Menggunakan Tangan Kanan dan Kiri Pada Musim 6 Tema Taman Mesra/Berkebun}

Gambar 5 adalah hasil screenshoot kegiatan motorik yang sesuai dengan tahapan anak usia 5-6 tahun sesuai Permendikbud No.137 Tahun 2014. Kegiatan ini berupa menghias ban bekas untuk dijadikan pot bunga. Terlihat Upin Ipin dan Fizi selain menghias ban bekas, mereka juga melatih kekuatan otot tangan dan kiri dengan memeindahkan ban pot yang dilakukan secara gotong royong.
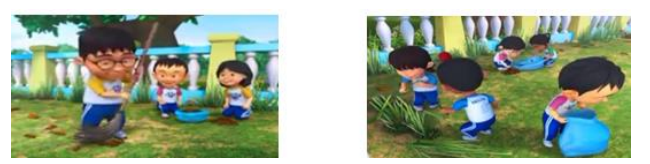

\section{Gambar 6. Melakukan Kegiatan Kebersihan Pada Musim 6 Tema Taman Mesra/Berkebun}

Gambar 6 adalah hasil screenshot kegiatan motorik yang sesuai dengan tahapan anak usia 5-6 tahun sesuai Permendikbud No.137 Tahun 2014. Kegiatan ini berupa kegiatan kebersihan yang dilakukan di halaman sekolah. Terlihat Ehsan dkk sedang melakukan kegiatan menyapu, mencabut rumput dan juga membersihkan sampah. Kegiatan motorik ini selain membuat halaman menjadi bersih tetapi juga membuat tubuh anak menjadi sehat dengan melakukan kegiatan kebersihan.

\section{Simpulan}

Berdasarkan hasil observasi dan melalui kartu data yang terdapat pada film kartun Upin Ipin tentang kegiatan motorik kasar untuk anak usia 5-6 tahun berdasarkan tahapan perkembangan anak usia dini, membuktikan bahwa film ini efektif dan kegiatannya sesuai dengan anak usia 5-6 tahun. Hal ini dibuktikan melalui ketiga tema yang peneliti jadikan penelitian, yaitu pada "Musim 5 dengan Tema Sedia Mulai Bagian 1 dan 2, Musim 6 dengan Tema Taman Mesra, dan Musim 11 dengan Tema Jom Hidup Sihat". Musim 5 pada tema "Sedia Mulai bagian 1 dan 2" menampilkan kegiatan melakukan gerakan koordinasi untuk melatih kelenturan, keseimbangan dan kelincahan, serta menampilkan kegiatan melakukan permainan fisik dengan tawuran, yaitu, kegiatan bergelayutan pada kegiatan pemanasan, hulahoop, menggiring bola dengan zig-zag, lompat tali, engklek, bakiak, dan tarik tambang. Musim 6 pada tema "Taman Mesra" menampilkan kegiatan melakukan kegiatan kebersihan dan terampil dalam menggunakan tangan kanan dan kiri. Musim 11 pada tema "Jom Hidup Sihat" menampilkan kegiatan koordinasi untuk melatih kelenturan, keseimbangan dan kelincahan dan juga menirukan senam irama. Kegiatan motorik kasar yang ada pada film Upin Ipin juga memberikan dampak terhadap keterampilan motorik kasar anak, yaitu anak dapat mengembangkan kreativitasnya melalui kegiatan-kegiatan motorik. Anak juga dapat berlatih dengan cara mendapatkan stimulus yang tepat dengan cara mengamati, mencontoh dan menerapkannya, sehingga motorik anak dapat tumbuh dan berkembang dengan optimal. 


\section{Daftar Rujukan}

Baan, A. (2020). Perkembangan Motorik Kasar Anak Usia Dini. Jurnal Bungamputi, 6(1).

Decaprio, R. (2017). Paduan Pengembangan Kecerdasan Motorik Siswa. Yogyakarta: Diva Press

Hurlock, E. B. (1978). Perkembangan Anak Edisi 6 Jilid 1. Jakarta: Erlangga.

Nugraheni, S. E., Wulandari, R. T., \& Anisa, N. (2019). Efektifitas permainan sirkuit mahkota untuk menstimulus kemampuan motorik kasar anak TK A di TK Dharma Wanita 06 Kedungkandang. Jurnal PAUD: Kajian Teori dan Praktik Pendidikan Anak Usia Dini, 1(2), 124-131.

Nurwita, S. (2019). Analisis Nilai-nilai Agama dan Moral Anak Usia Dini Dalam Tayangan Film Kartun Upin dan Ipin. Jurnal Obsesi, 3(2).

Permendikbud No.137 Tahun 2014. Tentang Standar Nasional Pendidikan Anak Usia Dini

Purnamasari, R. Y. (2020). Pengaruh Film Kartun Upin Ipin Terhadap Perilaku Anak. Jurnal Edukasi, 1(2).

Romlah. (2017). Pengaruh Motorik Halus dan Motorik Kasar Terhadap Perkembangan Kreatifitas Anak Usia Dini. Jurnal dan Ilmu Tarbiyah, 2(2).

Triyana, F. (2017). Peningkatan Kemampuan Fisik Motorik Kasar Melalui Metode Gerak Dan Lagu Pada Anak Usia Dini Di RA RowosariKecamatan Tuntang Kabupaten Semarang Tahun Pelajaran 2016/2017. 